\title{
Rancang Bangun Alat Untuk Mengukur Kadar Kekeruhan Pada Air Menggunakan Kamera Pada Remotely Operataed Vehicle (Rov) Dengan Metode Color Filtering
}

\author{
Chrisyangga Solina Adhi Permana \\ Jurusan Teknik Elektro, Fakultas Teknik dan Ilmu \\ Kelautan, Universitas Hang Tuah Surabaya \\ Jl. Arief Rachman Hakim no 105, Sukolilo, \\ Surabaya 60111, Jawa Timur \\ Email : chrisya.sap@gmail.com
}

\author{
M. Taufiqurrohman \\ Jurusan Teknik Elektro, Fakultas Teknik dan Ilmu \\ Kelautan, Universitas Hang Tuah Surabaya \\ Jl. Arief Rachman Hakim no 105, Sukolilo, \\ Surabaya 60111, Jawa Timur \\ Email : -
}

\begin{abstract}
Abstrak- Lebih dari 2/3 luas Indonesia adalah laut. Begitu juga dengan bumi, lebih dari $2 / 3$ bagian bumi atau dunia ini adalah lautan, karena itu usaha - usaha untuk menciptakan teknologi yang bisa memajukan dunia kelautan dari masa kemasa selalu berkembang. Karena itu, Indonesia memiliki kekayaan alam yang melimpah yang berasal dari laut. Selain itu juga air merupakan sumber daya paling penting bagi manusia akan tetapi seiring berjalannya waktu, kualitas air di Indonesia ini semakin berkurang. Hal itu disebabkan oleh ulah tangan-tangan jahil dari manusia yang mencemari sumber - sumber air di sekitarnya. Kemudian dimulailah projek penelitian dan juga perlindungan terhadap kualitas air di Indonesia yang cukup efektif, namun terbilang mahal. Oleh karena itu, pada penelitian ini memanfaatkan ROV tersebut yaitu tentang Rancang Bangun Alat Untuk Mengukur Kadar Kekeruhan Pada Air Menggunakan Kamera Pada Remotely Operated Vehicle (ROV) Dengan Metode Color Filtering.Hasil dari penelitian ini adalahROV akan mampu memonitoring kadar kekeruhan air pada suatu ekosistem
\end{abstract}

Kata kunci: Image Processing, Laut, ROV, Monitoring Air

\section{Pendahuluan}

Indonesia adalah negara kepulauan yang memiliki laut sangat luas, dan juga merupakan negara maritim terbesar di dunia. Lebih dari $2 / 3$ luas Indonesia adalah laut. Begitu juga dengan bumi, lebih dari $2 / 3$ bagian bumi atau dunia ini adalah lautan, karena itu usaha-usaha untuk menciptakan teknologi yang bisa memajukan dunia kelautan dari masa kemasa selalu berkembang. Laut memiliki keanekaraga-man yang melimpah dan unik, di laut kita bisa menemukan makhluk hidup dari jenis hewan hingga jenis tumbuhan, dari yang berukuran besar hingga kecil, dari yang berfungsi sebagai pangan, obat-obatan bahakan untuk perhiasaan ada di laut [1].

Melihat semua potensi yang sangat menjanjikan dari sumber daya laut, apa lagi laut Indonesia yang berada dikawasan tropis yang kaya raya, tidak berlebihan kiranya bahwa usaha - usaha untuk meningkatkan teknologi yang dapat mengarap semua potensi yang kita miliki semakin gencar dilaksanakan, bahakan bisa dikatakan bahwa kita harus untuk melakukan penelitaian - penelitian tentang robot dan teknologi yang bisa memberikan kita kemudahan dalam mengelola dan memanfaatkan sumberdaya laut yang kita miliki.

Berdasarkan hal-hal tersebut maka pada penelitian ini dikembangkan tentang salah satu fitur dari ROV atau Remotedly Operated vehicle. ROV merupakan robot kelautan yang memiliki kemampuan untuk mengamati benda benda yang ada dilautan. Keistimewaan alat ini adalah karena fungsinya yang memberikan kemudahan pada manusia untuk tidak perlu masuk dan menyelam kelautan dalam mengamati berbagai kondisi di bawah laut yang akan di amati. Dengan ROV seorang peneliti hanya perlu melihat data-data yang di tampilakn oleh ROV yang di masukan ke laut.

Teknologi robot bawah air (ROV) dalam aplikasinya ternyata telah menghasilkan efisiensi kinerja bila dibandingkan dengan cara konvensional, bahkan ROV mampu menjalankan tugas yang teknologi konvensional tidak mampu melakukannya [2].

ROV yang dioperasikan diperairan Indonesia untuk berbagai kegiatan kelautan belum dapat disediakan sepenuhnya oleh industri dalam negeri. Ketergantungan terhadap penggunaan produk luar negeri dapat melemahkan ketahanan negara khususnya ekonomi dan industri, untuk mengantisipasi hal 
tersebut maka dituntut supaya teknologi bawah air khususnya teknologi perancangan ROV dapat dikuasai [3].

\section{BaHAN DAN METodE}

Dalam melakukan kegaiatan penelitian ini akan di jelaskan sistem yang akan di buat berdasarkan diagram blok yang ada pada Gambar 1. Secara keseluruhan, konfigurasi sistem dari alat monitoring kadar kekeruhan air menggunakan kamera ini terdiri dari input, mikrokontroler, dan output.

Berdasarkan diagram blok pada Gambar 1, proses monitoring kadar kekeruhan air akan menggunakan kemera yang akan dikirim ke PC dan nantinya akan diproses dengan metode color filteriing, sehingga nanti dapat ditentukan kindisi air berdasarakan warna yang sudah di tentukan sebagai paramater. Lalu kamera juga akan bergerak sesuai arahan dari PC.

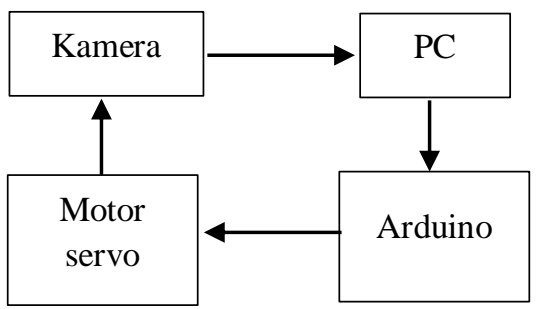

Gambar 1. Diagram Blok Alat

Proses pengambilan data nantinya akan menggunakan kamera yang mengambil beberapa gambar dari bawah air untuk kemudian di proses menjadi beberapa tahap, tahap dalam pemrosesan adalah sebagai berikut:

\section{Capture/Pengambilan Gambar}

Proses capture atau pengambilan gambar adalah kamerea nanti akan mengambil beberapa gamabr dari bawah air sekaligus menampilkan secara realtime kondisi bawah air

\section{Pemrosesan ke Grayscale}

Pada tahap ini gambar yang telah diambil nanti akan dirubah menjadi gambar grayscale atau gambar abu-abu sehingga memudahkan dalam proses selanjutnya, selain itu juga proses yang kita gunakan juga masih menggunakan format warna RGB sehingga harus di rubah kedalam grayscale.

\section{Thresholding}

Pada tahap ini kita menentukan batas dari sebuah gambar agar nantinya dapat diubah kedalam gambar binner, setelah di tentukan batasnya nanti gambar yang termasuk kedalam batas akan berubah menjadi putih (255) dan yang tidak termasuk akan jadi hitam (0).
Kamera ini digunakan untuk mendeteksi kadar kekeruahan air berdasarkan gambar yang di ambil oleh kamera nantinya. Kamera akan meng-capture gambar yang ditampilkan di layar PC lalu di olah sesuai dengan metodenya. Kamera yang digunakan adalah jenis action cam bertipe Bpro Alpha Edition. Kamera ini memiliki resolusi sebesar 12MP dana kemampuan merekam sampai 1080P.

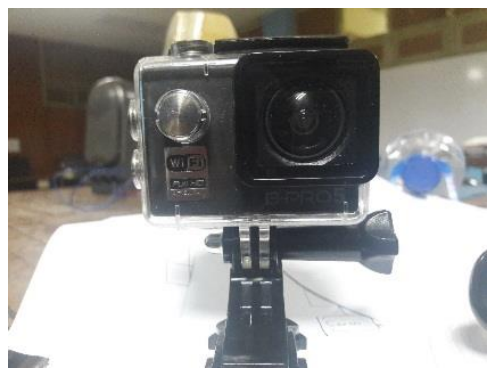

Gambar 2. B-Pro 5 Alpha Edition

\section{Image Processing (Pengolahan Citra)}

Image processing adalah suatu bentuk pengolahan atau pemrosesan sinyal dengan input berupa gambar (image) dan ditransformasikan menjadi gambar lain sebagai keluarannya dengan teknik tertentu. Image processing dilakukan untuk memperbaiki kesalahan data sinyal gambar yang terjadi akibat transmisi dan selama akuisisi sinyal, serta untuk meningkatkan kualitas penampakan gambar agar lebih mudah diinterpretasi oleh sistem penglihatan manusia baik dengan melakukan manipulasi dan juga penganalisisan terhadap gambar [4].

Pengolahan citra digital mampu mengidentifikasi jenis banyaknya objek-objek pada suatu citra. Contoh aplikasinya adalah menghitung jumlah sel darah merah (entrosit) yang rusak atau mengtahui kondisi sel darah, menghitung volume dari sampel citra gelembung yang diakibatkan air laut, dan menghitung jumlah gelembung pada citra gelembung sabun [4].

Pengolahan citra digital (Digital Image Processing) adalah sebuah disiplin ilmu yang mempelajari tentang teknik-teknik mengolah citra. Citra yang dimaksud disini adalah gambar diam (foto) maupun gambar bergerak (yang berasal dari webcam) [5].

Operasi pengolahan citra digital umumnya dilakukan dengan tujuan memperbaiki kualitas suatu gambar sehingga dapat dengan mudah diinterpretasikan oleh mata manusia dan untuk mengolah informasi yang ada pada suatu gambar untuk kebutuhan identifikasi objek secara otomatis [3]. 

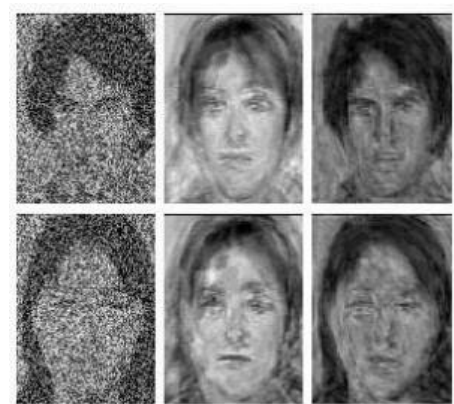

Gambar 3. Hasil Image Processing [6]

Citra biner (binary image) adalah citra digital yang hanya memiliki 2 kemungkinan warna, yaitu hitam dan putih. Citra biner disebut juga dengan citra W\&B (White \&Black) atau citra monokrom. Hanya dibutuhkan 1 bit untuk mewakili nilai setiap piksel dari citra biner.

Pembentukan citra biner memerlukan nilai batas keabuan yang akan digunakan sebagai nilai patokan. Piksel dengan derajat keabuan lebih besar dari nilai batas akan diberi nilai 1 dan sebaliknya piksel dengan derajat keabuan lebih kecil dari nilai batas akan diberi nilai 0 .

Citra biner sering sekali muncul sebagai hasil dari proses pengolahan, seperti segmentasi, pengambangan, morfologi ataupun dithering. Fungsi dari binerisasi sendiri adalah untuk mempermudah proses pengenalan pola, karena pola akan lebih mudah terdeteksi pada citra yang mengandung lebih sedikit warna.

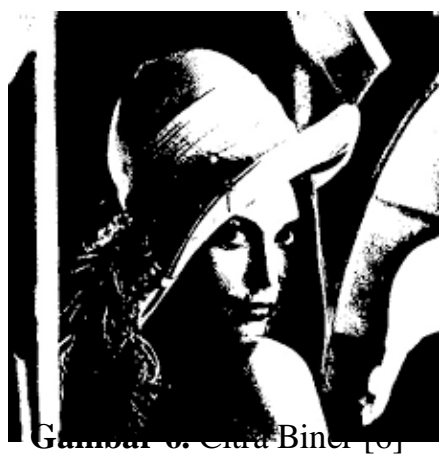

\section{Perancangan Software}

Perangkat lunak merupakan salah satu bagian terpenting dalam merancang suatu sistem. Karena perangkat lunak berfungsi untuk menaplikasikan metode sehingga didapat hasil yang valid. Dalam pembuatan perangkat lunak, digunakan Visual Studio 2012 dan openCV 2.4.9 dengan menggunakan visual studio yang di integrasikan dengan openCV 2.4.9 program dapat berjalan sesuai dengan yang di harapkan. OpenCV (Open Source Computer Vision Library) adalah sebuah pustaka perangkat lunak ISSN 2615-5788 Print (2615-7764)

(C)2020 JURNAL TEKNIK ELEKTRO DAN KOMPUTER TRIAC Vol. 7 No. 1 Tahun 2020 yang ditujukan untuk pengolahan citra dinamis secara real-time, yang dibuat oleh Intel, dan sekarang didukung oleh Willow Garage dan Itseez.

Metode yang digunakan adalah color filtering. Color Filtering adalah suatu teknik pengolahan citra yang yang dipakai untuk memanipulasi suatu citra berdasarkan warna spesifik. Cara kerjanya adalah dengan membandingkan komponen warna setiap pixel citra dengan warna spesifik. Apabila warnanya sesuai dengan warna spesifik komponen warna pixel tersebut dibiarkan saja. Namun, bila warnanya tidak sesuai dengan warna spesifik maka komponen warna pixel tersebut diubah menjadi warna background, biasanya menjadi warna hitam.

Jadi gambar yang ditampilkan akan melalui proses tersebut sehingga dapat ditentukana kondisi air tersebut apakah bening, keruh, atau jenuh. Berdasarkan nilai binner yang di dapat setelah proses thresholding atau proses binerisasi gambar dan berikut adalah flowchart dari alat yang akan dikerjakan.

Program dimulai dengan inisialisasi program terlebih dahulu. Lalu memulai untuk menampilkan gambar setalah gambar muncul baru lah mulai ptroses proses yang dilakukan anatra lain, convert to graysale, Thresholding, dan pembacaan biner. Convert to grayscale, adalah peroses perubahan gambar yang berwarna menjadi gambar abu - abu, dirubah ke graysale gunanya untuk memudahkan proses thresholding, proses thresholding sendiri adalah teknik yang sederhana tapi efektif untuk segmentasi citra.

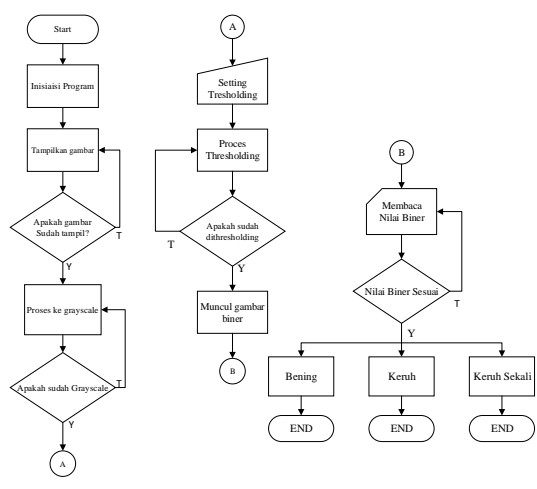

Gambar 7. Flowchart program

Proses Thresholding sering disebut dengan proses binerisasi. Setelah proses thresholding berhasil nantinya program akan membaca nilai biner yang di hasilkan pada suatu citra, dan kemudian di golongankan sesuai 
parameter yang ada. Dan akhirnya pun di peroleh hasil - hasil sesuai binner yang di dapatkan pada saat pengujian.

Dari flowchart bisa dilihat ada beberapa proses yang dilakukan sesuai dengan button yang diberikan. Proses - proses yang dilakukan dalam metode antara lain proses grayscale, dan Thresholding. berikut layout dari program yang dirancang pada tugas akhir ini.

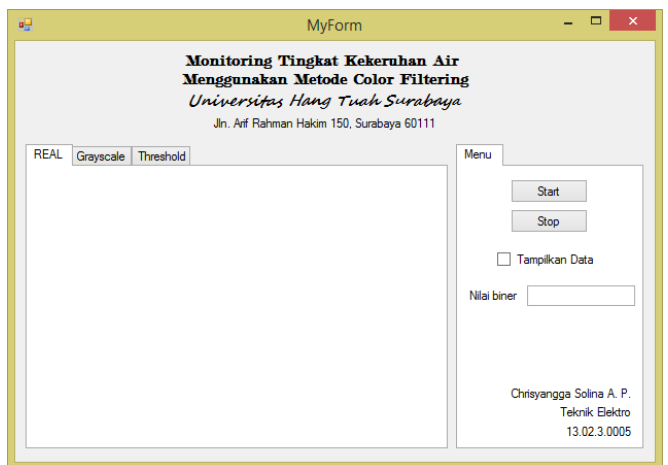

Gambar 8. Layout dari program

Pada Gambar 8 bisa dilihat kalau tampilan program dalam penelitian ini, program ini memiliki 2 tampilan yang pertama adalah citra warna dan citra biner. Citra warna ini menunjukan kondisi sebenarnya diwaktu alat ini di uji coba. Sedangkan citra biner ini adalah citra hasil pengolahan citra warna yang di proses menggunakan image proscessing sesuai dengan metode yang digunakan berupa color filtering.

\section{HASIL DAN PEMBAHASAN}

Pengujian dan analisa sistem merupakan tahap akhir yang akan di catat pada hasil dan pembahasan dari realisasi penelitian. Tahap ini merupakan tahap yang paling penting untuk mengetahui tingkat keberhasilan, keunggulan dan kekurangan dari sistem tersebut. Dengan begitu dapat diketahui sistem yang telah direalisasikan menghasilkan keluaran yang diinginkan. Pengujian dan analisa yang dilakukan meliputi sistem secara keseluruhan.

\section{Pengujian Kamera Pada air sangat keruh}

Percobaan kamera dibawah air pertama dilakukan pada air jernih, pada percobaan kali ini air jernih di taruh beberapa objek. Berikut adalah hasil dari percobaan di air jernih.

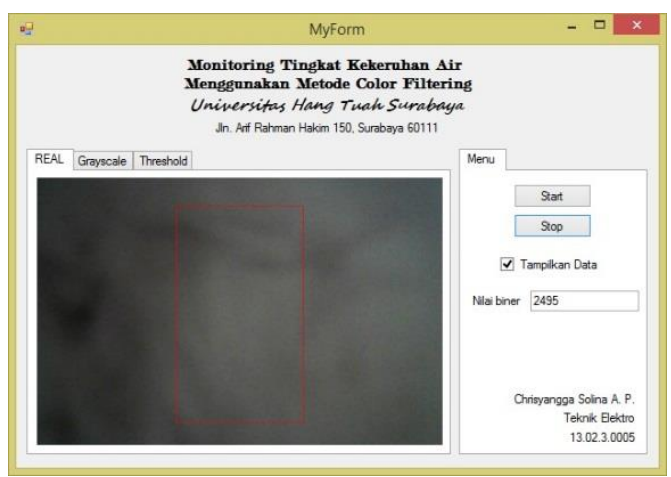

Gambar 9. Gambar asli air sangat keruh

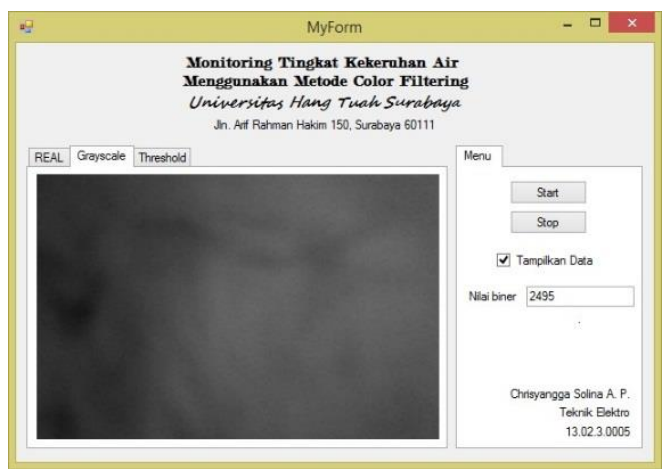

Gambar 10. Gambar grayscale air jernih

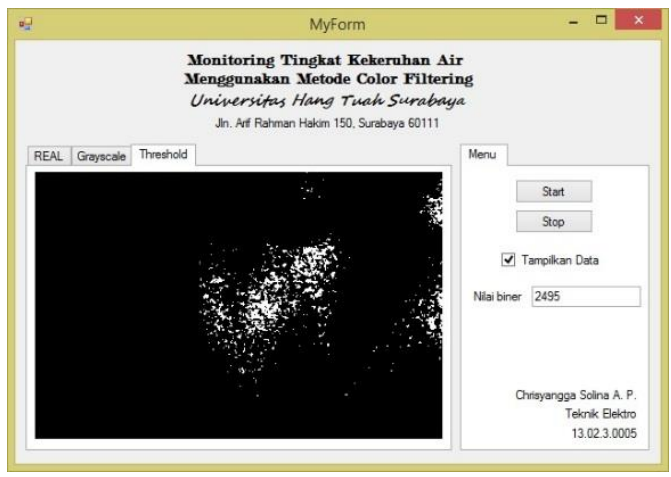

Gambar 11. Gambar biner air sangat keruh

Berdasarkan ketiga gambar diatas dapat dilihat nilai biner putih pada air keruh. Berikut adalah tabel hasil percobaan pada air sangat keruh.

Tabel 1. Percobaan kamera pada bawah air sangat keruh

\begin{tabular}{|c|c|c|}
\hline No & Percobaan & $\begin{array}{c}\text { Nilai Binary Image } \\
\text { Putih }\end{array}$ \\
\hline 1 & Percobaan 1 & 2495 \\
\hline 2 & Percobaan 2 & 3055 \\
\hline
\end{tabular}




\begin{tabular}{|l|c|l|}
\hline 3 & Percobaan 3 & 24015 \\
\hline 4 & Percobaan 4 & 34005 \\
\hline 5 & Percobaan 5 & 35000 \\
\hline \multicolumn{2}{|c|}{ Rata - Rata } & 19714 \\
\hline
\end{tabular}

Setelah melakukan perancangan dan pebuatan alat dilakukan beberapa percobaan di beberapa lokasi berbagai kondisi air pengambilan data gambar dari setiap kondisi air dan akhirnya di peroleh data berikut:

Tabel 2. Hasil uji coba dengan berbagai kondisi air

\begin{tabular}{|c|c|c|c|}
\hline NO & $\begin{array}{c}\text { JENIS } \\
\text { SAMPLE }\end{array}$ & $\begin{array}{c}\text { NILAI } \\
\text { BINNER }\end{array}$ & HASIL \\
\hline 1 & Sample 1 & 18600 & Jernih \\
\hline 2 & Sample 2 & 18100 & Jernih \\
\hline 3 & Sample 3 & 17525 & Jernih \\
\hline 4 & Sample 4 & 16500 & $\begin{array}{c}\text { Agak } \\
\text { keruh }\end{array}$ \\
\hline 5 & Sample 5 & 16333 & Keruh \\
\hline 6 & Sample 6 & 16755 & $\begin{array}{c}\text { Agak } \\
\text { Keruh }\end{array}$ \\
\hline 7 & Sample 7 & 12310 & Keruh \\
\hline
\end{tabular}

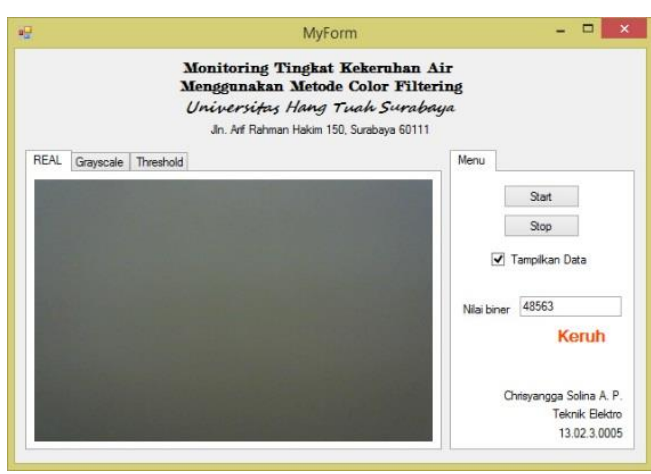

Gambar 12. Tampilan software untuk mendeteksi air keruh

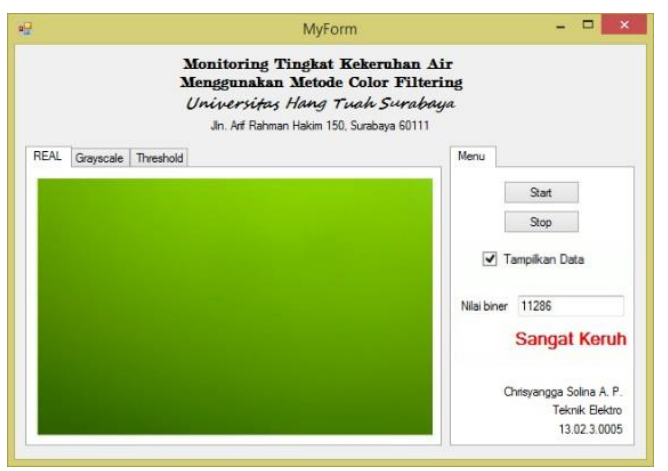

Gambar 13. Tampilan software untuk mendeteksi air sangat keruh

ISSN 2615-5788 Print (2615-7764)

(C)2020 JURNAL TEKNIK ELEKTRO DAN KOMPUTER TRIAC Vol. 7 No. 1 Tahun 2020

\section{KESIMPULAN}

Berdasarkan analisia dan pembahasan hasil penelitian dari beberapa percobaan didapat kesimpulan sebagai berikut:

1. Program sudah berjalan seperti yang diharapkan, ketika alat diuji di lapangan dan di uji dengan air di dalam wadah program sudah mampu menunjukan hasil sesuai dengan parameter yang di buat.

2. Hasil tangkapan gambar kamera dipengaruhi oleh faktor cahaya jika mendapat cahaya yang berlebih kamera akan menangkap warna jadi pucat, sedangkan jika cahaya kurang kamera mengirim gambar gelap.

3. Pada uji coba di air yang di campur dengan warna merah, biru, hijau diperoleh nilai rata rata untuk merah 52022, biru 59827, dan hijau 64853.

\section{Daftar Pustaka}

[1] Santoso H. 2013. Remotely Operated Vehicle (ROV). http://theoceanand mariner.blogspot.co.id/2013/10/remotelyoperated-vehicle-rov.html $[05$ Sep tember 2016]

[2] Christ, Robert D, dan Robert L Wernli Sr. 2007. The ROV Manual : A User Guide for Observation-Class Remotely Operated Vehicle. Elsevier Ltd. Oxford

[3] Taufiqurrohman M, Prayogi U, Winarno A. 2016. Rancang Bangun Remotely Operated Vehicle (ROV) sebagai Sarana Observasi Bawah Air. Prosiding Seminakel XI, pp C1 7891. Hang Tuah Press: Surabaya.

[4] Tharom T. 2003. Pengolan Citra pada Mobil Robot. Bandung: ITB

[5] Yuh J. 1990. Modeling and Control of Underwater Robotic Vehicles. IEEE Transactions on Systems, Man, and Cybernetics. Vol. 20, No. 6.

[6] http://www.invisiblefiction.com/image _processing.html 